\title{
Comparative Study of Impedance Spectroscopy between Nickel-Metal Hydride and Lithium-ion Batteries
}

\author{
Salim Erol ${ }^{1 *}$ \\ ${ }^{1 *}$ Eskisehir Osmangazi University, Faculty of Engineering and Architecture, Department of Chemical Engineering, Eskisehir, Turkey, (ORCID: 0000-0002-7219- \\ 6642), esalim@,ogu.edu.tr
}

(1st International Conference on Applied Engineering and Natural Sciences ICAENS 2021, November 1-3, 2021)

(DOI: 10.31590/ejosat.993325)

\begin{abstract}
ATIF/REFERENCE: Erol, S. (2021). Comparative Study of Impedance Spectroscopy between Nickel-Metal Hydride and Lithium-
\end{abstract} ion Batteries. European Journal of Science and Technology, (28), 144-151.

\begin{abstract}
Two commonly used commercially available rechargeable batteries, nickel-metal hydride battery and lithium-ion battery, have been investigated by impedance spectroscopy technique, which is a fast and an effective electrochemical method. These batteries were brought to the same potential and their electrochemical impedance properties in the equal frequency range were compared. The electrochemical characterization of the batteries was done by impedance analysis and equivalent circuit modeling. In addition, the physical parameters that are important for energy storage systems have been obtained with the developed equivalent circuit based mathematical model. The obtained parameters were compared in terms of battery performance and capacity characteristics that significantly determine the selection of batteries in energy storage systems. As a result of these processes, it has been determined that the lithium-ion battery has many advantages over the nickel-metal hydride battery in terms of battery dynamics. Furthermore, it is thought that the method used and the model obtained in this study can form the basis for the development of laboratory-scale and noncommercial batteries and to determine their ability to meet energy needs.
\end{abstract}

Keywords: Electrochemical impedance spectroscopy, rechargeable battery, equivalent circuit model, battery performance, porous electrode.

\section{Nikel-Metal Hidrit ve Lityum-iyon Piller Arasındaki Empedans Spektroskopisinin Karşılaştırmalı Çalışması}

$\ddot{O} \mathbf{z}$

Yaygın olarak kullanılan iki ticari şarj edilebilir pil, nikel-metal hidrit pil ve lityum-iyon pil, hızlı ve etkili bir elektrokimyasal yöntem olan empedans spektroskopisi tekniği ile incelenmiştir. Bu piller aynı potansiyele getirilerek eşit frekans aralığındaki elektrokimyasal empedans özellikleri karşılaştırılmıştır. Pillerin elektrokimyasal karakterizasyonu empedans analizi ve eşdeğer devre modellemesi ile yapılmıştır. Ayrıca geliştirilen eşdeğer devre tabanlı matematiksel model ile enerji depolama sistemleri için önemli olan fiziksel parametreler elde edilmiştir. Elde edilen parametreler, enerji depolama sistemlerinde pil seçimini önemli ölçüde belirleyen pil performansı ve kapasite özellikleri açısından karşılaştırılmıştır. Bu işlemler sonucunda lityum-iyon pilin batarya dinamiği açısından nikel-metal hidrit pile göre birçok avantajı olduğu tespit edilmiştir. Ayrıca, bu çalışmada kullanılan yöntem ve elde edilen modelin laboratuvar ölçekli ve ticari olmayan pillerin geliştirilmesine ve enerji ihtiyacını karşılama kabiliyetlerinin belirlenmesine temel oluşturabileceği düşünülmektedir.

Anahtar Kelimeler: Elektrokimyasal empedans spektroskopisi, şarj edilebilir pil, eşdeğer devre modeli, pil performansı, gözenekli elektrot.

*Corresponding Author: $\underline{x x x x @ x x x . x x . x x}$ 


\section{Introduction}

The need for diversification of renewable energy sources and the rapid increase in electric transportation have increased the importance of electrochemical energy storage in recent years. The transformation of vehicles used today into electric vehicles instead of internal combustion engines is of great importance in terms of the environment and our quality of life [1]. Applications in this innovative field require energy storage on a large scale and require high energy and high-power energy storage systems with robustness, low price $[2,3]$. However, the increase in the need for portable electronic and electrical devices in recent years has brought the need for high performance batteries.

Batteries used in energy storage are divided into two groups as primary (non-rechargeable) and secondary (rechargeable) batteries. Lead-acid, nickel-cadmium, nickel-iron, nickel-zinc, silver-zinc, silver-cadmium, zinc-manganese, nickel-metal hydride, and lithium-ion batteries are rechargeable batteries. Nickel-metal hydride (Ni-MH) and lithium-ion (Li-ion) batteries are widely used in energy storage applications due to their features such as high energy density, long usage times, fast charging, and suitable operating ranges in terms of both potential and temperature. [4].

Ni-MH batteries were discovered in the 1960s and have been commercially available since 1989 for power tools, robots, vacuum cleaners, electric toys, cordless phones, cell phones, emergency lighting systems, laptop computers, calculators, portable recorders, toys, photography. and video equipment, wireless mice and keyboards, hybrid electric vehicles, industrial energy storage and energy storage systems for light rail systems [5-7]. Ni-MH batteries have many important features compared to other battery technologies such as wide temperature operating range, long usage time and high specific power. These features have led many researchers and the energy market to work on these batteries in recent years [6]. In the Ni-MH battery, hydrogen absorbing metal alloy (metal hydride, $\mathrm{MH}$ ) is used as the positive electrode, while nickel oxyhydroxide, which is reduced to nickel hydroxide in case of discharge, is used as the negative electrode [8]. The positive and negative electrodes of cylindrical $\mathrm{Ni}-\mathrm{MH}$ batteries are separated by a separator. This separator prevents short circuit between the electrodes, allows current flow in the structure, provides ion diffusion and separates different electrode reactions from each other. In this type of $\mathrm{Ni}-\mathrm{MH}$ batteries, potassium hydroxide and some additives that will keep the $\mathrm{KOH}$ concentration constant during the charge-discharge processes of the battery are used as electrolyte [7]. The electrochemical reactions in a basic Ni-MH battery are given below [7]:

$\mathrm{M}+\mathrm{H}_{2} \mathrm{O}+\mathrm{e}^{-} \leftrightarrow \mathrm{OH}^{-}+\mathrm{MH}$

$\mathrm{Ni}(\mathrm{OH})_{2}+\mathrm{OH}^{-} \leftrightarrow \mathrm{NiOOH}+\mathrm{H}_{2} \mathrm{O}+\mathrm{e}^{-}$

The reaction taking place at the negative electrode (anode) is shown in Equation 1. $\mathrm{M}$ is a metal that can reversibly store hydrogen, and the hydride alloy is denoted $\mathrm{MH}$. The potential applied during the charging process splits the water molecule into a proton and a hydroxide ion. The protons formed are transported to the surface of the $\mathrm{MH}$ alloy particles and from there into the alloy stack with a repulsive force arising from the potential and diffusion difference. During the discharge process, the protons follow the opposite path. Equation 2 indicates the reaction at the positive electrode (cathode). During the charging process, the protons separate from $\mathrm{Ni}(\mathrm{OH})_{2}$ and move to the cathode surface e-ISSN: 2148-2683 and combine with the hydroxide ions in the electrolyte [6]. Thus, electrical energy can be converted into chemical energy by hydrogenation of hydrogen atoms into metal hydride alloys at the negative electrode and by oxidation of nickel hydroxide electrodes at the positive electrode [4].

Li-ion batteries were discovered in 1980 and started to be used commercially since the early 1990s [8]. Since the amount of energy that can be stored per unit volume and weight is high in Li-ion batteries, it has been preferred to be used in many portable electronic devices such as mobile phones, laptop computers and power devices. Li-ion batteries have increasing applications in a wide variety of fields, such as electric vehicles and stationary energy storage systems in domestic and commercial environments. Li-ion battery was first used commercially in 1991 [9]. Sony and Asahi Kasei have developed the first rechargeable Li-ion battery using graphite as the anode and lithium cobalt oxide $\left(\mathrm{LiCoO}_{2}\right)$ layers as the cathode. The increasing interest in the Liion battery in the world has made the Li-ion battery very popular over other secondary batteries such as $\mathrm{NiCd}$, Ni-MH and Pb-acid. In 1996, different positive electrode materials such as lithium iron phosphate $\left(\mathrm{LiFePO}_{4}\right)$ and other phospho-olivines were started to be used [10]. In addition to $\mathrm{LiCoO}_{2}$ and $\mathrm{LiFePO}_{4}$, lithium manganese oxide, lithium nickel cobalt aluminum oxide and lithium nickel manganese cobalt oxide components can be used as positive electrode materials. The most common negative electrode is graphite, high energy density silicon and long-life lithium titanate are under development as negative electrodes.

The charge/discharge process of the Li-ion battery is realized by the intercalation process of lithium ions enter between the layers in the electrodes and move between the electrodes [8]. The general electrochemical reactions in a Li-ion battery are given below:

$\mathrm{Li}^{+}+6 \mathrm{C}+\mathrm{e}^{-} \leftrightarrow \mathrm{LiC}_{6}$

$\mathrm{LiMO}_{2} \leftrightarrow \mathrm{MO}_{2}+\mathrm{Li}^{+}+\mathrm{e}^{-}$

The reaction that takes place at the anode in Li-ion batteries is shown in Equation 3. In the charged state, $\mathrm{a} \mathrm{Li}^{+}$ion is directed to the cathode using an external circuit while passing through the electrolyte consisting of organic solvents such as ethyl carbonate, dimethyl carbonate, propane carbonate and lithium hexafluorophosphate $\left(\mathrm{LiPF}_{6}\right)$ or lithium tetrafluoroborate $\left(\mathrm{LiBF}_{4}\right)$ salts to graphite $\left(\mathrm{C}_{6}\right)$. In the discharge state, the $\mathrm{Li}^{+}$ions separate from the graphitic anode settles between the metal oxide $\left(\mathrm{MO}_{2}\right)$ layers at the cathode and forms the $\mathrm{LiMO}_{2}$ compound. This reaction taking place at the cathode is given in Equation 4. In Equations 1-4, the forward arrows show charging, the backward ones show discharging reactions.

The high energy density of Ni-MH batteries, their safe storage and long-term use expectation still enable $\mathrm{Ni}-\mathrm{MH}$ batteries to be used in applications such as electric hybrid vehicles [11]. Li-ion batteries, on the other hand, stand out among the most promising technologies in the field of energy storage with their features such as high specific energy, specific power and long shelf life compared to other battery technologies such as $\mathrm{Pb}$-acid and Ni-MH [12]. However, today many battery manufacturers offer a wide range of products for both individual and corporate customers. However, for many batteries, obtaining reliable information and determining battery characteristics can be quite difficult. Top companies provide guides containing technical product information such as size, weight, capacity, potential profile, and charge/discharge life as well as some measurement 
methods that support these numerical data, along with the batteries and batteries they produce. Lower-priced products are medium-capacity batteries that do not contain any measurement information. Some of these low-priced batteries attempt to indicate battery quality with non-valid tests. Since very few of the consumers of private or small commercial batteries have devices and equipment to test the batteries they use, manufacturers with cheap batteries may present some false information to make their products compete with higher quality products. This affects battery selection in commercial or individual applications and the performance in applications where batteries are used [9]. Academic studies that will provide sensitive and accurate information about the quality and use cases of commercially used $\mathrm{Ni}-\mathrm{MH}$ and Li-ion batteries are a necessity.

The developments in Ni-MH and Li-ion battery technologies, which are the two leading battery types in the secondary battery market, have accelerated the commercial application of these batteries in plug-in hybrid vehicles, hybrid electric vehicles and battery electric vehicles. Li-ion batteries are generally $50 \%$ lighter and $25-30 \%$ smaller than Ni-MH batteries. This has revealed the advantages such as easier application of Li-ion batteries to vehicles, more power generation for acceleration increase, energy storage of the battery through the regenerative braking system with mechanical electrical energy conversion and increased energy efficiency. However, although the power packs consisting of Li-ion batteries have remarkable advantages, Ni-MH battery packs are also used for energy storage due to the fact that they are economical in many of today's hybrid vehicles [12].

In the selection of batteries to be used in the application, there are a wide range of battery features that are very important and must be considered. Size, weight, and shape are important physical properties. Commercial Li-ion batteries come in a variety of sizes and shapes. The most common type of Li-ion battery is the cylindrical 18650 batteries with a diameter of $18 \mathrm{~mm}$ and a length of $65 \mathrm{~mm}$. The 18650 batteries produced for use in laptop computers has been made suitable for use in various power devices, electric bicycles, portable applications, and automotive applications (for example, electric cars of Tesla Motors) due to its advantageous properties $[9,13]$. Considering the Li-ion batteries, the wide usage area of the 18650 batteries has made the studies with this battery interesting and increased [9]. For this reason, studies with $18650 \mathrm{Li}$-ion batteries are of great importance in the field of energy storage.

The monitoring of the charge and capacity status of the batteries is of great importance in order to make maximum use of the batteries. In this context, there are two important terms for energy storage systems: state of charge (SoC) and state of health $(\mathrm{SoH}) . \mathrm{SoC}$ is defined as a measure of the amount of charge the battery can give during its use, while $\mathrm{SoH}$ is defined as a relative measure of the battery's current usable capacity with respect to its initial use. The information that can be obtained about these two terms provides users with important impressions about the current energy capacity of the battery [14]. However, there are important deficiencies in determining the charge states of the batteries correctly and in meeting the requirements for battery management systems and charging infrastructure for various electric vehicles [15].

Battery packs are of great importance in the transition from fossil fuel vehicles to zero-emission vehicles [16]. In the design of battery packs, many factors that affect the battery configuration, such as energy/power ratio, potential range, maximum current, and temperature range, must be considered. However, the total needed battery potential determines how many batteries should be connected in series or parallel. What is important here is the capacity of the batteries to be used and the number of connections that will be needed when these batteries are used. The industry has not yet reached a complete conclusion in determining the standard battery capacities of electric vehicles. In addition, Tesla electric vehicles use many 18650 cylindrical batteries in series and parallel configuration with a capacity of 2 $3 \mathrm{Ah}$, while other electric vehicles use larger pack batteries of about $20 \mathrm{Ah}$ each. This affects the battery pack design [8].

Today, the processes taking place in battery packs are of great importance in terms of fully understanding, development and safety, and studies in this area are increasingly intensified in the world [16]. However, the measurement difficulties in the load state and the difficulties in interpreting the data related to electrochemical processes and physical parameters limit their applications in practical areas [14]. Electrochemical impedance spectroscopy (EIS) technique has emerged as one of the techniques used in recent years to overcome the difficulties encountered in this context [16]. EIS is a fast and valid method that allows the battery to be evaluated in its natural environment and does not have destructive effects by reaching the dynamic response in load situations [14]. With the EIS method, it is possible to examine the response of an electrochemical system with small signal effects, and it is a very effective technique where it is possible to identify and analyze any point of the system [15]. Besides being widely used for electrochemical batteries as an analytical method, EIS also has important uses for sensor systems, corrosion processes and various other energy storage devices [17] EIS tests are performed by applying a low amplitude alternating current (ac) wave command signal at different frequencies. If the input signal applied during EIS measurement is current, galvanostatic analysis will be performed, while if the input signal is potential, potentiostatic analysis will be performed. From here, the impedance value is a transfer function calculated by the ratio of potential and current at each tested frequency [14].

Models such as electrochemical model, mechanical model and equivalent circuit model have been started to be developed for the estimation of various parameters of batteries and battery systems. However, a battery model with numerical efficiency and high accuracy has not been developed yet [18]. Recently, the simulation of battery impedance data at different charge levels, which also takes into account the diffusion process, can be modeled with the equivalent circuit model. Thus, the way to interpret the impedance data has been opened. In addition, modelbased impedance analysis aims to better understand the mechanisms that cause a decrease in battery performance and battery capacity under different battery conditions $[9,13,14]$. However, the definition of an equivalent circuit model is also important for understanding the physical events that occur in the battery during the charge/discharge processes and determining the methods to be used to evaluate the utility status [15].

The EIS method can characterize electrochemical processes with Nyquist representation of the negative of the imaginary part of the impedance $\left(-Z_{j}\right)$ as a function of the real part of the impedance $\left(Z_{r}\right)$ obtained at different frequencies. Fig. 1 shows a Nyquist plot of a standard electrochemical system called a Randles circuit. In simple terms, the Nyquist plot of the impedance response of the Randles circuit, which is the equivalent circuit of the system in which an electrochemical reaction and a linear diffusion take place, is an ohmic resistance 
$\left(\mathrm{R}_{\mathrm{e}}\right)$ with the cutoff value in the high frequency region, a double layer capacitance $\left(\mathrm{C}_{\mathrm{dl}}\right)$ seen as a semicircle in the mid-frequency region. ) and a parallel charge transfer resistor $\left(\mathrm{R}_{\mathrm{t}}\right)$ and a Warburg impedance element $\left(Z_{W}\right)$ observed as a line with a slope of 1 in the low frequency region $[15,17]$. The diameter of the midfrequency semicircle represents the $\mathrm{R}_{\mathrm{t}}$ value. This model shows that both the reaction kinetics and the diffusion process affect the impedance. While the $\mathrm{R}_{\mathrm{t}}$ and $\mathrm{C}_{\mathrm{dl}}$ elements are related to the reactions in the electrochemical system, the $Z_{W}$ element represents the linear diffusion process. In simple terms, $\mathrm{R}_{\mathrm{t}}$ defines the resistance of charged ions to be adsorbed on the electrode surface, $C_{\mathrm{dl}}$ defines the capacitance value between these charged ions and the electrode surface, and $\mathrm{Z}_{\mathrm{W}}$ defines the distance of the travels of the reactants diffused in the active material and is an indicator of the diffusion-limiting reactions occurring in the system [17].

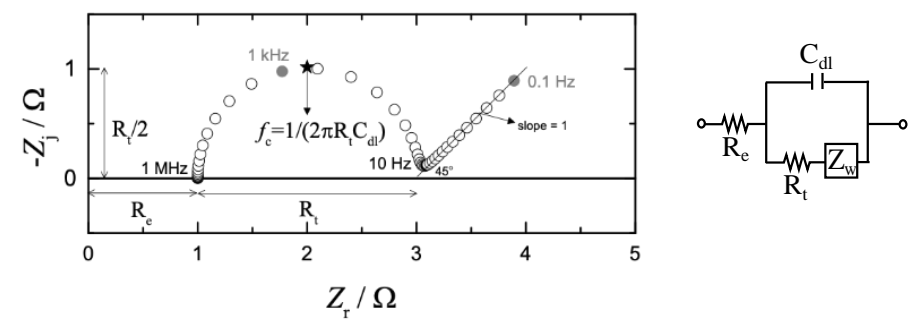

Fig. 1 The simulation of an impedance spectrum in Nyquist format for the Randles circuit shown on the right handside. Here, the values of the circuit elements are $R_{e}=1 \Omega, R_{t}=2 \Omega$, $C_{d 1}=100 \mu F$, Warburg impedance, $Z_{W}(f)=A_{W} / \sqrt{2 \pi j f}$ with Warburg coefficient, $A_{W}=1 \Omega \mathrm{s}^{-0,5}$, and characteristic frequency $f_{c}=797,55 \mathrm{~Hz}$ [19].

Suppressed semicircles found in the impedance spectra of electrochemical systems show that some improvements are needed in the Randles circuit to develop the circuit model. The suppressed semicircles can be caused by surface roughness and varying thickness of the electrodes, uneven current and inhomogeneous reaction rate. Usually, these half-circles are represented as a non-physical circuit element called a constant phase element (CPE) in equivalent electrical circuit representation of impedance [14].

In the Nyquist representation of rechargeable batteries, the separation of ions from the electrolyte or electrodes (electrochemical reactions and kinetics) in the high-medium frequency $(\mathrm{kHz}-\mathrm{Hz})$ region, and the diffusion of ions and mass transfer effects in the low frequency $(\mathrm{Hz}-\mathrm{mHz})$ region can be defined. Electrochemical double layer capacitance and charge transfer in this layer can be observed in the high-mid frequency region between $\mathrm{kHz}-\mathrm{Hz}$. Inductance (L) resulting from electromagnetic effects can be observed at $\mathrm{kHz}$ and higher frequencies [2]. However, since most electrical applications do not occur at high frequency, inductive behavior can be neglected [12]. Thus, information about the processes occurring in battery packs formed by batteries and battery systems at various frequencies can be obtained.
In this study, it is proposed to investigate the electrochemical properties of commercially available Ni-MH and Li-ion batteries by performing charge, discharge, and impedance measurements at room temperature. The batteries were brought to the same potential and their electrochemical impedance properties in the equal frequency range were compared. The electrochemical characterization of the batteries was done by impedance analysis and equivalent circuit modeling.

\section{Material and Method}

\subsection{Materials and Instrumentation}

Electrochemical analyzes and equivalent circuit mathematical modeling were performed using the Gamry Reference 3000 Potentiostat/Galvanostat device and its software. In electrochemical analysis, Duracell brand 6HR61 model Ni-MH battery (width: 24.5 ) mm, height: $46.5 \mathrm{~mm}$, thickness: $17.5 \mathrm{~mm}$, operating potential range: $7.0-9.5 \mathrm{~V}$, capacity: $1700 \mathrm{mAh}$ ) and Sony brand 18650 model Li-ion batteries (diameter: $18 \mathrm{~mm}$, height: $65 \mathrm{~mm}$, operating potential range: 3.0-4.2 V, capacity: $3000 \mathrm{mAh}$ ) are used. The Gamry Framework within the Reference 3000 Potentiostat/Galvanostat purchased from Gamry Instruments was used to perform electrochemical impedance measurements, as well as charging and discharging. The potentiostat was connected to a desktop computer. All the impedance data gathered was regressed in the Gamry Echem Analyst built in the computer.

\subsection{Method}

First, open circuit potential (OCP) measurements of the Liion battery for 5 minutes were done at one-second intervals. Two Li-ion batteries were charged separately to a cell potential of $4 \mathrm{~V}$ in two steps by applying a constant current. The total cell potential of two Li-ion batteries was brought to $8 \mathrm{~V}$ by connecting the Gamry device in series with the help of the battery holder. OCP measurements were taken for 2 minutes after each procedure. The potentiostatic EIS analyzes of Li-ion batteries with a potential of $8 \mathrm{~V}$ were performed with an alternating current of $10 \mathrm{mV}$ amplitude in the frequency range of $100 \mathrm{kHz}-10 \mathrm{mHz}$.

For the Ni-MH battery, OCP measurement was performed for 5 minutes at one-second intervals. The 6HR61 Ni-MH battery pack, consisting of 6 series-connected $1.5 \mathrm{~V}$ potential Ni-MH batteries, was discharged gradually. The galvanostatic EIS analysis of the $8 \mathrm{~V}$ potential Ni-MH battery was carried out with an alternating current of $10 \mathrm{~mA}$ in the frequency range of 100 $\mathrm{kHz}-10 \mathrm{mHz}$.

All experiments were performed at room temperature (approximately $20{ }^{\circ} \mathrm{C}$ ) and experiments with the same type of battery were repeated 3 times to ensure results were both consistent and reproducible. Consistent and precise procedures have been enabled to reduce errors between the software in the Gamry instrument and repeated experiments. In addition, the reliability of all impedance data obtained was confirmed by examining the Kramers-Kronig relationship [19]. 


\section{Results and Discussion}

\subsection{Charge and Discharge}

OCP measurement was performed to determine the initial cell potential of the $18650 \mathrm{Li}$-ion battery and the initial potential was determined to be $3.50 \pm 0.02 \mathrm{~V}$. After this process, the cell potential of each battery was gradually increased to $3.75 \mathrm{~V}$ and then to 4.00 V. These charging processes were carried out with chronopotentiometry, in which a constant current of $1 \mathrm{~A}$ is applied and the potential is increased, and then chronoamperometry, where the potential is kept constant and the current approaches zero by slowly decreasing the current.

OCP measurement was performed to determine the initial cell potential of the $6 \mathrm{HR} 61 \mathrm{Ni}-\mathrm{MH}$ battery, and the initial potential was determined to be $8.50 \pm 0.02 \mathrm{~V}$. After this process, the cell potential of the Ni-MH battery was discharged galvanostatically by applying a constant current of $17 \mathrm{~mA}$ - the standard discharge current written on the battery - and OCP measurement was taken for 2 minutes after the $8 \mathrm{~V}$ potential was reached. As a result of this measurement, it was determined that the battery was selfcharged to $8.40 \pm 0.02 \mathrm{~V}$ potential. Then, a second discharge was carried out by reducing the discharge current to $5 \mathrm{~mA}$ in order to prevent the battery from self-charging. As a result of this process, OCP measurement was carried out for 2 minutes to determine the cell potential, and after reaching $8 \mathrm{~V}$ potential, the potential increased to $8.20 \pm 0.02 \mathrm{~V}$ and it was observed that the battery was recharged by itself. After that, the discharge current was reduced to $1 \mathrm{~mA}$ and a third discharge was carried out. As a result of this process, OCP measurement was carried out for 20 minutes in order to determine the cell potential and it was observed that the battery potential was fixed at $8.00 \pm 0.02 \mathrm{~V}$.

\subsection{Impedance Analysis}

Impedance spectroscopy analyses were performed to examine in detail the electrochemical properties of $\mathrm{Li}$-ion and $\mathrm{Ni}$ $\mathrm{MH}$ battery packs brought to two equipotential potentials $(8 \mathrm{~V})$.

The Nyquist graph of the Li-ion battery is shown in Fig. 2. The impedance values (positive imaginary part) seen in the high frequency region $(100-2.5 \mathrm{kHz})$ in this graph are generally interpreted as an inductive effect in electrochemical processes [19]. However, there is no inductive effect in Li-ion batteries, or it is observed at very low levels, and it is thought that the impedance values in this frequency range are caused by the impedance response (noise) of the cables and connectors of the potentiostat device. Therefore, for $18650 \mathrm{Li}$-ion batteries, it is only possible to examine the electrochemical properties of the battery by performing impedance analysis with an initial frequency of less than $100 \mathrm{kHz}$ (for example, $3 \mathrm{kHz}$ ). The impedance data obtained in the mid-frequency $(2.5 \mathrm{kHz}-2.5 \mathrm{~Hz})$ region form a semicircle called the "capacitive loop". This semicircle in the Nyquist plot represents the reactions taking place at the electrodes inside the battery. In general, the first half circle at higher frequency shows the electrochemical reaction at the negative electrode (anode), and the second half circle at lower frequency shows the electrochemical reaction at the positive electrode (cathode). The desired electrochemical reaction at the anode is the placement of lithium ions, called intercalation, between graphite layers. However, lithium ions can form a solidelectrolyte interphase (SEI) on the graphitic anode by reacting with organic solvents from the electrolyte components in the charged state. The SEI layer is a passivating film formed on the surface of the active electrode material, as well as protecting the electrolyte and other battery components (especially the graphitic anode) from various undesirable reactions. The most common cause of capacity reduction in Li-ion batteries is the irreversible loss of Li-ions due to SEI formation [20]. Therefore, the charge transfer resistance of the SEI layer on the negative electrode is higher than the cathode resistance of the battery. As a result, it can be concluded that the impedance data with a wider semicircle belong to the negative electrode [19]. However, the total impedance values of two Li-ion batteries in series are observed as a single semicircle. The reason for this can be shown as the SEI layers do not develop much since both batteries are not yet subject to charge/discharge cycles. If the batteries are charged/discharged many times, it can be observed that the impedance values at higher frequency will form a larger semi-circle [19]. In the low frequency $(2.5 \mathrm{~Hz}-10 \mathrm{mHz})$ region, a line with a slope of approximately $51.5^{\circ}$ (with a slope greater than 1) is observed, which is the angle of impedance with the abscissa (real part axis). The linear impedance data in this region is formed by the diffusion of mobile ions in the electrochemical systems within the electrodes [19]. The slope of the line here gives information about the diffusion mechanism. It is shown in Fig. 1 that the slope of the line in the low frequency region observed in the impedance response of the Randles circuit is 1 . This indicates that ions in the relevant system have a diffusion mechanism that obeys Fick's second law. The fact that the slope of this line in the impedance of the Li-ion battery is greater than 1 indicates that the diffusion of lithium ions deviates from Fick's second law [19].

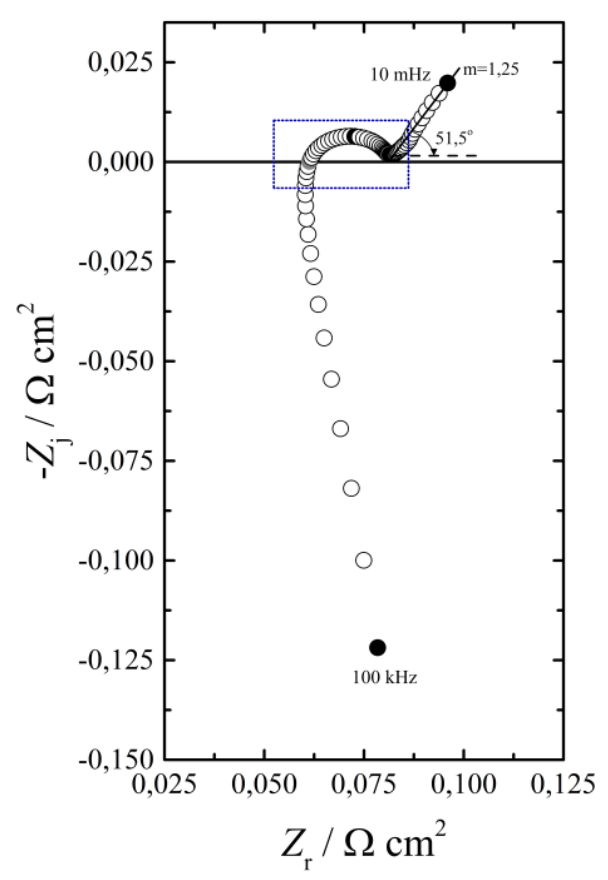

Fig. 2 Impedance response in Nyquist representation of two $18650 \mathrm{Li}$-ion cells connected in series at $8 \mathrm{~V}$ combined.

Capacitive-loop values are corresponding to the box.

Nyquist graph of Ni-MH battery is given in Fig. 3. The impedance values seen in the high frequency region $(100-25 \mathrm{kHz})$ in this graph are due to the impedance response (noise) of the cables and connectors of the potentiostat device of the battery. This value of the impedance of the Ni-MH battery is much lower than that of the Li-ion battery. It can be said that the frequency range chosen for the investigation of the electrochemical 
properties of the battery is more suitable for the Ni-MH battery. The impedance data obtained in the mid-frequency $(25 \mathrm{kHz}-2.5$ $\mathrm{Hz}$ ) region consists of at least one suppressed semicircle. The suppressed shape of the semicircles in the Nyquist diagram is related to the roughness and heterogeneity of the electrode surface [19]. The first half circle seen at higher frequency shows the electron transfer process occurring in the hydrogen oxidation reaction on the negative electrode surface. The second half circle, which is suppressed at a lower frequency, belongs to the charge transfer process occurring at the interface of the positive electrode and the electrolyte, and in this process, the reduction reaction of the active material, $\mathrm{NiOOH}$, takes place [13]. In the low frequency $(2.5 \mathrm{~Hz}-10 \mathrm{mHz})$ region, a straight line with an impedance angle of about $71.5^{\circ}$ and a slope of about 3 is observed. The diffusion mechanism of the hydrogen anion ( $\mathrm{H}-$, hydride) at the positive electrode is related to the linear impedance data in the low frequency region [4]. The fact that the slope of the line in the low frequency region of the Ni-MH battery is greater than 1 indicates that the diffusion of hydride ions deviates more from Fick's second law than that of lithium ions.

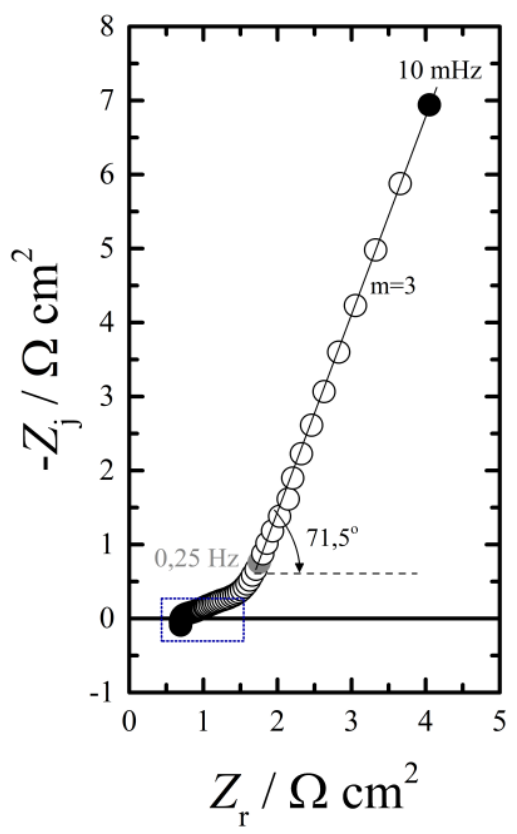

Fig. 3 Impedance response in Nyquist representation of 6 HR61 Ni-MH battery at $8 \mathrm{~V}$. Capacitive-loop values are corresponding to the box.

The impedance responses of two rechargeable batteries at equal cell potential $(8 \mathrm{~V})$ and in the same frequency range $(100$ $\mathrm{kHz}-10 \mathrm{mHz}$ ) differ. These differences indicate that the electrochemical properties of these two batteries are different. When the impedance spectra of the batteries under equal conditions (ambient temperature, cell potential, frequency range) were compared, it was determined that the impedance values of the Li-ion battery were much lower than that of the Ni-MH battery. This is evident from the Nyquist plots in Fig. 2 and 3. When the distinguishing features such as energy densities and capacities of Li-ion and Ni-MH batteries, which are commercially available today, are compared, it is seen that these features of the $\mathrm{Li}$-ion battery are far superior to those of the Ni-MH battery. This caused Li-ion batteries to be preferred more in systems with high energy needs. The impedance values, which were obtained experimentally quickly and consistently and were inversely e-ISSN: 2148-2683 proportional to the conductivity, made it possible to compare the ability of these two batteries to meet their energy needs. The low impedance values of the $18650 \mathrm{Li}$-ion batteries indicate high energy density, while the high impedance values of the 6HR61 Ni-MH battery indicate low energy density.

\subsection{Mathematical Model}

An electrochemical battery mainly consists of cathode, anode, electrolyte, separator and current collectors. Its total impedance can be composed of 5 main sources: (i) the cable and the inductive effect of metallic elements in the battery, $L$; (ii) the ohmic resistance of the battery, $R_{\mathrm{e}}$ (sum of the resistances of the electrolyte, separator, and current collectors); (iii) charge transfer resistors at the interface of the electrodes, $R_{\mathrm{t}}$; (iv) double layer capacitance, $C_{\mathrm{dl}}$ or stationary phase element, $C P E$, and (v) diffusion impedance in the electrode stack and active material, $Z_{\mathrm{d}}$ $[8,9,22]$. An equivalent circuit model needs to be defined to understand and analyze the impedance responses of batteries in more detail. Depending on the number and complexity of the layers and interfaces in the battery system, there can be many circuit elements in the equivalent circuit [23]. The impedance parameters listed above can be represented as equivalent electrical circuit elements to explain an electrochemical system. This approach is widely used to illustrate EIS process models [22].

In Fig. 4, the impedance of the reactions taking place at the positive electrode is shown by a charge transfer resistor $\left(R_{\mathrm{t}, \mathrm{c}}\right)$ and a stationary phase element $\left(C P E_{\mathrm{c}}\right.$, parameters are $Q_{\mathrm{c}}$ and $\left.\alpha_{\mathrm{c}}\right)$ parallel to this resistance. In addition, the impedance of the diffusion of mobile ions on the positive electrode is also indicated by $Z_{\mathrm{d}, \mathrm{c}}$, which is in series with the $R_{\mathrm{t}, \mathrm{c}}$ resistance. The contribution of the electrolyte and the separator to the impedance independent of the frequency is shown as the ohmic resistance $\left(R_{\mathrm{e}}\right)$. This resistance also includes the resistance values of the electrical connection areas of the battery (current collectors, etc.) and the separator. The impedance value corresponding to the reactions with the SEI layer on the negative electrode is represented by a charge transfer resistance $\left(R_{\mathrm{t}, \mathrm{a}}\right)$ in the anode region and the double layer capacitance $\left(C_{\mathrm{dl}, \mathrm{a}}\right)$ parallel to this resistance.

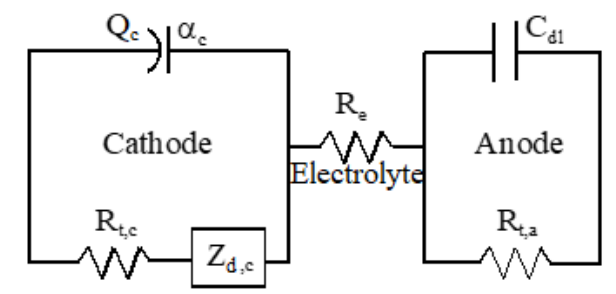

\section{Fig. 4 Equivalent circuit representation for impedances of} the Ni-MH and the Li-ion batteries

The battery overall impedance $(Z)$ consists of the anode $\left(Z_{\mathrm{a}}\right)$, electrolyte $\left(R_{\mathrm{e}}\right)$ and cathode $\left(Z_{\mathrm{c}}\right)$ impedances, which are the main components of the battery. Since these impedances are connected in series, the $Z$ value is expressed as the sum of these impedances as following

$Z=Z_{\mathrm{c}}+R_{\mathrm{e}}+Z_{\mathrm{a}}$

where $Z_{\mathrm{c}}$ is the cathodic impedance that can be defined as

$Z_{\mathrm{c}}=\frac{R_{\mathrm{t}, \mathrm{c}}+Z_{\mathrm{d}, \mathrm{c}}}{1+(\mathrm{j} \omega)^{\alpha} \mathrm{c}\left(R_{\mathrm{t}, \mathrm{c}}+Z_{\mathrm{d}, \mathrm{c}}\right) Q_{\mathrm{c}}}$

where $Z_{\mathrm{d}, \mathrm{c}}$ is the diffusion impedance at the cathode derived from the transmission line model (TLM) developed by Bisquert [24]. 
This mathematical model is derived for porous electrodes and generally expressed as

$Z_{\mathrm{d}, \mathrm{c}}=\sqrt{\frac{R_{\mathrm{m}} R_{\mathrm{k}}}{1+(\mathrm{j} \omega)^{\alpha} \mathrm{m} R_{\mathrm{k}} Q_{\mathrm{m}}}} \operatorname{coth}\left(L \sqrt{\frac{R_{\mathrm{m}}\left[1+(\mathrm{j} \omega)^{\alpha} \mathrm{m} R_{\mathrm{k}} Q_{\mathrm{m}}\right]}{R_{\mathrm{k}}}}\right)$

where $R_{\mathrm{m}}$ is the resistance of the electrolyte placed in the electrode pores, $R_{\mathrm{k}}$ and $C P E_{\mathrm{m}}$ (parameters of which are $Q_{\mathrm{m}}$ and $\left.\alpha_{\mathrm{m}}\right)$ are respectively the resistance and constant phase elements of the circuit elements corresponding to the active interface impedance of the pores, and $L$ is the dimensionless length of the TLM in the pore. In Equation (5), $Z_{\mathrm{a}}$ is the anodic impedance that can be defined as

$Z_{\mathrm{a}}=\frac{R_{\mathrm{t}, \mathrm{a}}}{1+\mathrm{j} \omega R_{\mathrm{t}, \mathrm{a}} C_{\mathrm{dl}, \mathrm{a}}}$

In Equations (6)-(8), $\mathrm{j}$ expresses the imaginary complex number, and $\omega$ is angular frequency.

In Table 1, when the charge transfer resistances of the batteries are compared, it is seen that the anodic resistance for the $\mathrm{Li}$-ion battery is higher than the cathodic resistance, while it is low for the Ni-MH battery. The SEI layer seen on the negative electrode of $\mathrm{Li}$-ion batteries can be said to be the reason why the anodic resistance is higher than the cathodic resistance. In Ni-MH batteries, the reason why the cathodic resistance is greater than the anodic resistance can be attributed to the absence of a layer on the negative electrode that can cause an extra resistance like SEI. It has been determined that the anodic, cathodic and electrolyte resistance values of the Ni-MH battery are much higher than those of the Li-ion battery. The higher ohmic resistance in the Ni-MH battery indicates that the battery's discharge capacity and charge/discharge cycle capability are weak. The sum of the internal resistances of energy storage devices is an important performance indicator, and a low resistance value indicates high performance. In this study, it was determined that Li-ion batteries have much higher performance compared to Ni-MH batteries. The $\alpha$ value, which is the exponential of the stationary phase element, is an indicator of the electrode surface roughness and usually has

\section{Conclusions and Recommendations}

In this study, electrochemical impedance analysis at the same cell potential, constant temperature, and frequency range was performed for commercial 6HR61 type Ni-MH and 18650 type $\mathrm{Li}$-ion batteries which are commonly used secondary batteries. The significant physical parameters for batteries were determined by the impedance responses and the developed equivalent circuit model of these two rechargeable batteries. As a result, the lithiumion battery has several superior properties over the nickel-metal hydride battery. In addition, the equivalent circuit and mathematical model developed with the electrochemical impedance spectroscopy technique has been shown to be effective and has a great potential for meeting the energy needs and design of future batteries.

\section{Acknowledge}

This work was supported by the Scientific Research Foundation at Eskisehir Osmangazi University under grant number 2017-1911. a value between 0.5 and $1 . \alpha$ value close to 1 indicates that the roughness is low. When the ac values of the Li-ion battery and the Ni-MH battery are compared, it has been determined that the Liion battery has a value closer to 1 . This indicates that the positive electrode surface is smoother for the 18650 Li-ion battery. Likewise, an $\alpha_{\mathrm{m}}$ value closer to 1 indicates that the pores of the Li-ion battery on the positive electrode are also smoother than the Ni-MH battery. The $Q$ parameter, which is the coefficient of the stationary phase element, is an indicator of the battery capacity. A high $Q$ value indicates that the ability of the electrode to adsorb mobile ions to the surface is also high. The fact that the $Q_{\mathrm{c}}$ and $Q_{\mathrm{m}}$ values of the Li-ion battery are much higher than those of the $\mathrm{Ni}$ $\mathrm{MH}$ battery indicates that the adsorption of ions to both the electrode surface and the pores of the Li-ion battery is higher. Finally, when the electrolyte resistance and charge transfer resistances in the pores are compared, it is seen that the Ni-MH battery has higher values than the Li-ion battery. As a result of all these comparisons, it has been revealed that the $18650 \mathrm{Li}$-ion battery has much superior features than the 6HR61 Ni-MH battery in many ways in terms of battery dynamics as well as capacity and performance.

Table 1. Regression results of equivalent circuit model parameters for batteries

\begin{tabular}{|c|c|c|}
\hline Parameter & 6HR61 Ni-MH & 18650 Li-ion \\
\hline$C_{\mathrm{dl}, \mathrm{a}} / \mathrm{F} \mathrm{cm}^{-2}$ & 0.06022 & 0.03038 \\
\hline$R_{\mathrm{t}, \mathrm{a}} / \Omega \mathrm{cm}^{2}$ & 0.1255 & 0.01363 \\
\hline$R_{\mathrm{e}} / \Omega \mathrm{cm}^{2}$ & 0.7022 & 0.05973 \\
\hline$Q_{\mathrm{c}} / \mathrm{F} \mathrm{cm} \mathrm{cm}^{-2} \mathrm{~s}^{\alpha-1}$ & 0.002638 & 0.4709 \\
\hline$\alpha_{\mathrm{c}}$ & 0.8375 & 0.9747 \\
\hline$R_{\mathrm{t}, \mathrm{c}} / \Omega \mathrm{cm}^{2}$ & 0.1604 & 0.01070 \\
\hline$R_{\mathrm{m}} / \Omega \mathrm{cm}^{2}$ & 1.902 & 0.1779 \\
\hline$R_{\mathrm{k}} / \Omega \mathrm{cm}^{2}$ & 4647 & 0.007223 \\
\hline$Q_{\mathrm{m}} / \mathrm{F} \mathrm{cm} \mathrm{cm}^{-2} \mathrm{~s}^{\alpha-1}$ & 1.24 & 3852 \\
\hline$\alpha_{\mathrm{m}}$ & 0.7698 & 0.9135 \\
\hline$L$ & 0.9797 & 0.1172 \\
\hline
\end{tabular}

\section{References}

[1] Etacheri, V., Marom, R., Elazari, R., Salitra, G., Aurbach, D., "Challenges in the development of advanced Li-ion batteries: a review”, Energ. Environ. Sci., 4 (9), 3243-3262, 2011.

[2] Din, E., Schaef, C., Moffat, K., Stauth, J.T., “A scalable active battery management system with embedded real-time electrochemical impedance spectroscopy", IEEE T. Power Electr., 32 (7), 5688-5698, 2017.

[3] Mulder, G., Omar, N., Pauwels, S., Meeus, M., Leemans, F., Verbrugge, B., De Nijs, W., Van den Bossche, P., Six, D., Van Mierlo, J., "Comparison of commercial battery cells in relation to material properties", Electrochim. Acta, 87, 473488, 2013.

[4] Zhu, W.H., Zhu, Y., Tatarchuk, B.J., "Self-discharge characteristics and performance degradation of Ni-MH batteries for storage applications", Int. J. Hydrogen Energ., 39 (34), 19789-19798, 2014.

[5] Morimoto, K., Nagashima, I., Matsui, M., Maki, H., Mizuhata, M., "Improvement of electrochemical properties and oxidation/reduction behavior of cobalt in positive electrode of Ni-metal hydride battery", J. Power Sources, 388, 45-51, 2018. 
[6] Yan, S., Nei, J., Li, P., Young, K.H., Simon Ng, K.Y., "Effects of $\mathrm{Cs}_{2} \mathrm{CO}_{3}$ additive in $\mathrm{KOH}$ electrolyte used in Ni/MH batteries", Batteries, 3 (4), 41, 2017.

[7] Tarabay, J., Karami, N., "Nickel metal hydride battery: structure, chemical reaction, and circuit model", Third International Conference on Technological Advances in Electrical, Electronics and Computer Engineering (TAEECE), Beirut, Lebanon, 29 April-1 May, 2015.

[8] Ed. Yan J., Rechargeable Battery Energy Storage System Design, Handbook of Clean Energy Systems. Hoboken, NJ, USA: John Wiley \& Sons, 2801-2819, 2015, vol. 5.

[9] Muenzel, V., Hollenkamp, A.F., Bhatt, A.I., de Hoog, J., Brazil, M., Thomas, D.A., Mareels, I., "A comparative testing study of commercial 18650-format lithium-ion battery cells", J. Electrochem. Soc., 162 (8), A1592-A1600, 2015.

[10] Balasundaram, M., M., Ramar, V., Yap, C., Li, L., Tay, A.A., Balaya, P., "Heat loss distribution: Impedance and thermal loss analyses in $\mathrm{LiFePO}_{4} /$ graphite 18650 electrochemical cell", J. Power Sources, 328, 413-421, 2016.

[11] Piłatowicz, G., Marongiu, A., Drillkens, J., Sinhuber, P. and Sauer, D.U., "A critical overview of definitions and determination techniques of the internal resistance using lithium-ion, lead-acid, nickel metal-hydride batteries and electrochemical double-layer capacitors as examples", $J$. Power Sources, 296, 365-376, 2015.

[12] Castano-Solis, S., Serrano-Jimenez, D., Gauchia, L. and Sanz, J. "The influence of BMSs on the characterization and modeling of series and parallel Li-ion packs", Energies, 10 (3), 273, 2017.

[13] Zhu, Y., Zhu, W.H., Davis, Z., Tatarchuk, B.J., "Simulation of Ni-MH batteries via an equivalent circuit model for energy storage applications", Advances in Physical Chemistry, 2016, 4584781, 2016.

[14] Robinson, J.B., Darr, J.A., Eastwood, D.S., Hinds, G., Lee, P.D., Shearing, P.R., Taiwo, O.O. and Brett, D.J., "Nonuniform temperature distribution in Li-ion batteries during discharge-A combined thermal imaging, X-ray microtomography and electrochemical impedance approach", $J$. Power Sources, 252, 51-57, 2014.

[15] Galeotti, M., Giammanco, C., Cinà, L., Cordiner, S. and Di Carlo, A., "Synthetic methods for the evaluation of the State of Health (SOH) of nickel-metal hydride (NiMH) batteries", Energ. Convers. Manage., 92, 1-9. 2015.

[16] Wolff, N., Harting, N., Heinrich, M., Röder, F. and Krewer, U., Nonlinear frequency response analysis on lithium-ion batteries: A model-based assessment, Electrochim. Acta, 260, 614-622, 2018.

[17] Ferg, E.E., van Vuuren, F., "Comparative capacity performance and electrochemical impedance spectroscopy of commercial AA alkaline primary cells", Electrochim. Acta, 128, 203-209. 2014.

[18] Yang, Q., Xu, J., Cao, B., Li, X., “A simplified fractional order impedance model and parameter identification method for lithium-ion batteries", Plos One, 12 (2), e0172424, 2017.

[19] Erol S., Impedance Spectroscopy Analysis and Modeling of Lithium-ion Batteries, Saarbrücken, Germany: Lambert Academic Publishing, 2016.

[20] Pinson, M.B., Bazant, M.Z., "Theory of SEI formation in rechargeable batteries: capacity fade, accelerated aging and lifetime prediction", J. Electrochem.Soc., 160 (2), A243A250, 2013.
[21] Bisquert J., Compte, A., "Theory of the electrochemical impedance of anomalous diffusion", J. Electroanal. Chem., 499, 112-120, 2001.

[22] Lvovich, V.F., Impedance Spectroscopy: Applications to Electrochemical and Dielectric Phenomena, Hoboken, NJ, USA: John Wiley \& Sons, 2012.

[23] Erol, S., "Process Model Development of Lithium-ion Batteries-An Electrochemical Impedance Spectroscopy Simulation", Sakarya University Journal of Science, 24(6), 1191-1197, 2020.

[24] Bisquert, J., "Influence of the boundaries in the impedance of porous film electrodes", Phys. Chem. Chem. Phys., 2 (18), 4185-4192, 2000. 